\section{APORTACIONES DE LA RETÓRICA A LA ESCRITURA CREATIVA EN CUANTO DISCIPLINA DOCENTE UNIVERSITARIA: UNA PROPUESTA}

\author{
José Manuel Mora-Fandos \\ Universidad Complutense de Madrid \\ ORCID iD: https://orcid.org/0000-0001-8593-4459 \\ jmora02@ucm.es \\ Christelle Schreiber-Di Cesare \\ Université de Lorraine \\ ORCID iD: https://orcid.org/0000-0003-3042-1052 \\ christelle.di-cesare@univ-lorraine.fr
}

\begin{abstract}
Cómo citar este artículo/Citation: Mora-Fandos, José Manuel y Schreiber-Di Cesare, Christelle (2020). Aportaciones de la retórica a la escritura creativa en cuanto disciplina docente universitaria: una propuesta. Arbor, 196 (798): a580. https:// doi.org/10.3989/arbor.2020.798n4004
\end{abstract}

Recibido: 25 mayo 2020. Aceptado: 31 octubre 2020.

RESUMEN: Escritura creativa es un término que apela a diversas posibilidades educativas y formativas a través del medio de la escritura. Para su realización concreta recurre a recursos y orientaciones procedentes de diversos saberes y disciplinas. Nuestra propuesta es acotar uno de estos significados de la escritura creativa y presentar su relación con la retórica, disciplina que puede aportar elementos significativos a los fines formativos de la escritura creativa, tal como la hemos acotado. Para esta acotación del significado narraremos primero brevemente la historia de su constitución, y a continuación su finalidad como realidad formativa. Sobre la base de esta finalidad delimitaremos a grandes rasgos la disciplina de la retórica y presentaremos sus posibles aportaciones a la escritura creativa.

PALABRAS CLAVE: Escritura creativa; retórica; poética; práctica.

\section{CONTRIBUTIONS OF RHETORIC TO CREATIVE WRITING AS A UNIVERSITY TEACHING DISCIPLINE: A PROPOSAL}

Copyright: (C) 2020 CSIC. Este es un artículo de acceso abierto distribuido bajo los términos de la licencia de uso y distribución Creative Commons Reconocimiento 4.0 Internacional (CC BY 4.0).
ABSTRACT: Creative writing is a term that recurs to various educational and training possibilities through the medium of writing. For its specific realization, it resorts to resources and orientations coming from diverse knowledge and disciplines. Our proposal is to select one of these meanings of creative writing and show its relationship to rhetoric, a discipline that can contribute significant elements to the formative purposes of creative writing as we have delimited it. For this determination of meaning, we first briefly relate the story of its creation and then its purpose as a formative reality. On the basis of this objective, we broadly define the discipline of rhetoric and present its possible contributions to creative writing. 


\section{INTRODUCCIÓN}

La escritura creativa es en la actualidad un fenómeno educativo y cultural pluriforme y capaz de adaptación a fines diversos. Así, aparece en ámbitos como el directamente literario, el del guion cinematográfico, el de la enseñanza primaria y secundaria, el de la terapia, y virtualmente en cualquier campo profesional, asistencial y educativo donde se pueda implicar la escritura para mejorar el rendimiento, la calidad de vida, el desarrollo personal, las relaciones interpersonales, la empatía, etc. De esta diversidad de fines y referencias, el presente artículo se centra en la escritura creativa en cuanto disciplina docente en el ámbito universitario; desde esta premisa, y teniendo en cuenta que la escritura creativa se ha abierto históricamente a una diversidad de disciplinas de las que ha tomado y toma recursos, abordaremos las posibilidades que le ofrece la retórica, apoyándonos en la larga historia de estrechas relaciones entre la construcción de discursos retóricos y de discursos literarios en Occidente.

\section{ESCRITURA CREATIVA, UNA BREVE HISTORIA}

El concepto escritura creativa, traducción del inglés creative writing, ha venido formándose durante un siglo y medio hasta nuestros días a través de un proceso complejo. Para observar sus posibles conexiones con la retórica, creemos conveniente presentar un sucinto recorrido histórico de esta formación y de sus rasgos principales.

Se atribuye la expresión "escritura creativa» al filósofo norteamericano Ralph Waldo Emerson en su ensayo The American Scholar de 1837 (1964: 51). Con ella quería significar una escritura opuesta a la de la erudición universitaria, y promover un nuevo modelo educativo donde se primara la sacralidad del acto creativo, la independencia de criterio, la experiencia directa y el desarrollo de los propios talentos. Según Myers (1993: 279-284), tras este primer precedente, la escritura creativa se configuró esencialmente durante un periodo comprendido entre 1880 y 1940 en el ámbito de la Universidad de Harvard, con el fin de reformar los estudios universitarios de literatura. Se quería trascender el enfoque unilateral filológico desde la experiencia de la escritura, como un modo vivo de conocimiento. El iniciador será Barrett Wendell (1855-1921), "escritor creativo» y uno de los primeros novelistas-profesores en el ámbito universitario norteamericano, quien renueva la asignatura de English composition, tradicionalmente basada en la imitación de textos latinos y dirigida al aprendizaje de reglas de estilo. Su propia experiencia de escritor (Wendell, 1893: 659) le había persuadido de que la buena escritura era amena $-\mathrm{y}$ en este sentido se distinguía de la escritura correcta-, y de que los auténticos escritores vivían en el mundo real, distinto del de los libros. Coincidía su asignatura con la de retórica en cuanto al sentido práctico dictado por las necesidades de la vida real; pero se distanciaba de ella por no compartir la alta tecnificación y reglamentación en la composición de los discursos ni la finalidad esencial de aquella: la persuasión. Por estas razones Wendell implementó novedades como la escritura diaria, el tema cotidiano, la autoexpresión, la experiencia personal vital, el gusto por la escritura o la prioridad de la idiosincrasia del alumno sobre las normas gramaticales. Su enfoque creó escuela (Fenza, 2000: 13), como lo atestigua uno de sus seguidores, Hughes Mearns (1929: 6-7), que elaboró antologías de textos escritos por alumnos según un enfoque creativo que principalmente reivindicaba la autoexpresión y la experiencia. Si bien recurría a la literatura para proponer ejemplos y sugerir lecturas con el objetivo del desarrollo personal de los alumnos, comprendía que su pedagogía también favorecía que algunos encontraran allí su vocación literaria.

Un factor nuevo para la configuración de la escritura creativa llega cuando en los años 20, desde el ámbito de los estudios literarios universitarios norteamericanos -en parte como una nueva reacción a la preponderante formación filológica-, se propone un acercamiento intrínseco, estético y de significado a las obras literarias (Myers, 2006: 122-145). Este enfoque crítico contempla la literatura como algo vivo y ve en el conocimiento experiencial -mediante la lectura atenta y la escritura creativamente orientada - un enriquecimiento de los estudios literarios. Serán principalmente los profesores de crítica literaria los que aportarán metodologías analíticas y prácticas de construcción literaria a las tradicionales asignaturas de English y $\mathrm{Li}$ terature. En estrecha conexión con esta orientación, aparece en los años 30 una corriente universitaria que se propone aunar una formación amplia y liberal junto con la más directamente vocacional y práctica. Así, Norman Foerster implementa en la Universidad de lowa su proyecto de la School of Liberal Arts cuyo objetivo es una formación más comprehensiva y actualizada de las disciplinas humanísticas (Myers, 2006: 124-125). Para mejorar la formación del estudiante de grado de Literature, Foerster integra en el profesorado de la escuela a filólogos, críticos literarios y escritores. Aunque el objetivo no es formar directamente escritores, admite a aquellos alumnos que buscan una educación artística y quieran beneficiarse de 
una instrucción en historia literaria, crítica y dominio del lenguaje que potencie su trabajo creativo. Sobre la base del trabajo de Foerster se institucionalizará más tarde en lowa la disciplina de la escritura creativa como formación de escritores en el nivel de posgrado, donde se contará principalmente con escritores para el trabajo docente. La pedagogía se estructurará sobre el taller de lectura de escritos de los alumnos y el seminario dirigido por un especialista, y se orientará ancilarmente al trabajo principal del alumno: la elaboración de una obra creativa final con la que obtener el Master in Fine Arts. De este periodo data la afluencia a importantes universidades norteamericanas de escritores que imparten asignaturas en programas de escritura creativa: en algunos casos son figuras ampliamente reconocidas como Robert Frost o Vladimir Nabokov, y en otros, escritores que desarrollan su carrera literaria al tiempo que se profesionalizan en este tipo de formación, como Wallace Stegner.

En 1967 el escritor R. V. Cassill funda la Association of Writing Programs (Fenza, 2000: 16) en la Universidad de Brown, motivado por la necesidad de los escritores-profesores universitarios de escritura creativa de asegurar la estabilidad de su profesión, determinar unos niveles altos de calidad y favorecer oportunidades de publicación para jóvenes escritores. Según McGurl (2009: x), desde el final de la II Guerra Mundial, las universidades norteamericanas se han convertido en los custodios de la literatura moderna, y en los formadores de la mayoría de los escritores y lectores serios del país. Gracias al desarrollo organizado del concepto de programa en escritura creativa, de un modo esforzado y continuado se ha generado un crecimiento sistémico de la excelencia en la literatura norteamericana, y una producción de ficción excelente y abundante como nunca había ocurrido (McGurl, 2005: 129 y 2009: 424-425).

Esta historia se ha circunscrito al ámbito norteamericano, siguiendo la propia naturaleza del fenómeno y la historiografía disponible. La escritura creativa empezó mucho más tarde en el ámbito español, a inicios de los años 80 del siglo XX, principalmente por el influjo de talleristas argentinos que desarrollan pedagogías inspiradas en la escritura comunal y en las teorías de Gianni Rodari, si bien esta línea se ha ido amalgamando con los esquemas de la tradición norteamericana hasta la actualidad (Coto, 1994; Obligado, 2014). Si el desarrollo en España no es tan amplio ni profundo como en Estados Unidos, sin embargo la diversidad de orientaciones mostradas allí va arraigando aquí -junto con recursos, fines y condiciones propias- a través de diversas implementaciones dentro y fuera de la universidad, donde han destacado instituciones privadas como la pionera Librería Fuentetaja en Madrid (Cañelles y Álvarez, 2007), y otras como la Escuela de Letras y Escuela de escritores, también en Madrid. En el ámbito universitario público destacan la Universidad de Sevilla, la Universitat Pompeu Fabra de Barcelona y la Universidad Complutense de Madrid, por citar las iniciadoras, con programas de posgrado orientados a la formación de escritores, y una idiosincrasia propia que en muchos aspectos se asemeja a las iniciativas de Norman Foerster en la School of Liberal Arts.

\section{BALANCE Y DELIMITACIÓN DE LA ESCRITURA CREATIVA PARA ESTE ARTÍCULO}

Tras este recorrido histórico, podemos decir que el término escritura creativa cubre una realidad plural que se puede resumir en:

1. La escritura creativa refiere directamente a una disciplina docente, no al ejercicio de una actividad productiva.

2. Puede significar un programa definido o una serie abierta de estrategias pedagógicas aplicables a diversos fines concretos a través de la escritura que, a grandes rasgos, se pueden resumir en tres: a) desarrollar la personalidad en una amplia variedad de ámbitos sociales, profesionales y asistenciales; b) complementar y ampliar una formación en estudios literarios; y c) contribuir a la formación de escritores literarios mediante un programa sistemático de aprendizaje y un ambiente comunitario de creación artística.

Los tres fines habitualmente se refieren a ámbitos formativos diferentes, específicos y dirigidos a tipos particulares de alumnos, pero las posibilidades de sinergia e interrelación son variadas, y pueden aunarse según diseños particulares. En cuanto a c), es habitual que la formación se entienda flexiblemente como una ayuda y entrenamiento en herramientas conceptuales, iniciación en hábitos útiles para el escritor en formación y un flujo constante e interactivo de experiencias de escritura; pero nunca rígidamente como una garantizada producción de escritores, y aún menos de escritores de éxito editorial. Como se indica actualmente en la web del programa de escritura creativa de la Universidad de lowa:

Aunque estamos de acuerdo en parte con la insistencia popular de que la escritura no se puede enseñar, nuestra razón de ser y proceder parte del 
supuesto de que el talento puede desarrollarse, y vemos nuestras posibilidades y limitaciones como escuela bajo esa luz. Si uno puede "aprender» a tocar el violín o a pintar, puede "aprender» a escribir, aunque ningún proceso de entrenamiento inducido externamente pueda asegurar que lo hará bien (https:// writersworkshop.uiowa.edu/about/about-workshop/ philosophy. Traducción nuestra).

En consonancia con y a partir de esta aquilatada experiencia, consideramos que la escritura creativa, en cuanto formación de escritores en un contexto universitario, puede encontrar en la retórica conceptos, orientaciones y recursos válidos para el desarrollo del talento del alumno, conjugables con pedagogías ya implementadas como el taller, asignaturas de crítica literaria aplicada, seminarios con escritores, clases de historia literaria, poética narratológica, lírica o dramatúrgica, el contacto asesor con profesionales del mundo editorial, periodos extensos tutorizados para la escritura... A continuación indicaremos algunos aspectos de la retórica que se prestan especialmente a esta relación con la escritura creativa.

\section{LA CONEXIÓN DE LA ESCRITURA CREATIVA CON LA RETÓRICA A TRAVÉS DE LA POETICA DOCENS}

Para resaltar las relaciones entre poética y retórica y la imbricación de la escritura creativa en estas relaciones, conviene recordar brevemente que la retórica (Whitla, 2009: 228) cuenta con una historia de al menos 2.500 años y se ha ejercitado tradicionalmente a través de la escritura y la oratoria, asentándose principalmente en la base canónica de las grandes sistematizaciones llevadas a cabo en la Retórica de Aristóteles (2005), el Sobre el orador de Cicerón (2002), la Retórica a Herenio (1997) y las Instituciones de oratoria de Quintiliano (1942), por citar las principales. Desde la época clásica grecolatina sus ámbitos originarios han sido la política cívica y la literatura, y se ha desarrollado en Occidente en instituciones jurídicas, religiosas y gubernamentales, además de seguir formando parte del plan de estudios en numerosas escuelas y universidades europeas y norteamericanas en la actualidad. Los estudios contemporáneos de retórica han ampliado su campo hasta incluir la práctica y el estudio de la comunicación efectiva en cualquier medio, en el discurso político y legal, así como en todo tipo de interacción social, en las artes, en ámbitos de alta cultura y de cultura popular, y en la literatura (Whitla, 2009: 227).

Si como indica C. S. Lewis (1954: 61) nuestra poesía antigua fue escrita y leída por hombres para quie- nes la distinción entre poética y retórica, tal como se entiende modernamente, no habría tenido sentido, conviene resaltar la distinción entre las dos sin separarlas (Garrido Gallardo, 2004: 191), adscribiendo específicamente a la primera la disciplina que se ocupa de la literatura, de la creación llevada a cabo mediante la palabra; y a la segunda la que se ocupa del discurso configurado para lograr la persuasión. Complementariamente, la cercanía o solapamiento parcial de las dos estriba, en una medida importante, en que los medios expresivos que se han puesto y ponen en la práctica para atraer la atención con una finalidad persuasiva, así como los medios compositivos para configurar el discurso han sido y continúan siendo, al menos en parte, los mismos que se emplean con una finalidad artística.

Kurt Spang (1998: 549) en su artículo «De nuptiis rhetoricae et poeticae», orientado a señalar la conexión entre retórica y poética, diferencia entre una poetica docens y una poetica utens: la primera comprendería la multisecular reflexión sobre la técnica compositiva literaria, así como el conocimiento de las normativas apriorísticas para su interpretación y evaluación, hasta incluir los desarrollos modernos y contemporáneos de la teoría de la literatura; la segunda indicaría directamente el ejercicio de la escritura. Análogamente, Spang retoma también la clásica distinción entre rhetorica utens, para designar la aplicación pragmática de la retórica, y rhetorica docens, para indicar la investigación y docencia de esta materia. Sobre este esquema, recuerda que la rhetorica docens ha estudiado y sistematizado medios expresivos y recursos compositivos en un valioso depósito de conceptos analíticos al que la poetica docens ha recurrido habitualmente a lo largo de su historia. A partir de esta conexión, consideramos que la escritura creativa entendida como formación de escritores en un contexto principalmente universitario puede ser vista con legitimidad como un modo pedagógico contemporáneo englobado en la poetica docens. De este modo participa de las fructíferas relaciones que poetica y rhetorica han mantenido a lo largo del tiempo por coincidir ambas en la finalidad general de elaborar eficazmente discursos, en una misma materia - la lengua - y en amplias zonas de solapamiento, aunque diverjan en las finalidades específicas, como ha indicado con precisión Paul Ricoeur (1997: 79-89). A continuación, indicaremos vías para el aprovechamiento de la retórica por parte de la escritura creativa. 


\section{EL SABER DISPOSICIONAL, RASGO COMÚN A LA RE- TÓRICA Y LA POÉTICA}

Desde mediados del siglo XX, en los trabajos de filósofos continentales centroeuropeos como $M$. Heidegger, H.-G. Gadamer, M. Riedl y P. Ricoeur, y de origen analítico anglosajón como W. v. O. Quine y N. Wilson, surge un replanteamiento de la idea de razón que busca liberarla del paradigma racionalista del conocimiento, predominante en la modernidad. A partir de nuevas lecturas de los textos aristotélicos se recupera la importancia de otros saberes que habían quedado relegados o silenciados, como el práctico-prudencial, el productivo y el de uso, así como la multiplicidad de formas de lo que se denomina el saber disposicional o saber-cómo, por oposición al saber proposicional o saber-qué (Vigo, 2011: 165166). Según Damschen (2011: 191), el saber-cómo es una propiedad disposicional del sujeto o forma de saber que consiste en la relación entre una persona y una habilidad práctica, y contrasta con el saber-qué, que expresa la que se da entre un sujeto epistémico y una proposición.

En este marco conceptual, el profesor de escritura creativa puede despertar la conciencia de que la competencia tanto en el ejercicio literario logrado poetica utens-, como en el esencialmente persuasivo - rhetorica utens-, dependen en buena parte de un saber disposicional adquirido con la práctica, que puede englobar y beneficiarse, en algún grado, de un saber-qué, proposicional, allegado por el conocimiento de la teoría literaria (desde las cuestiones más filosóficas hasta la narratología); y subrayar que el saber proposicional no es en modo alguno causa suficiente de la realización de obras literarias logradas. El beneficio de la conexión con la rhetorica docens en cuanto saber disposicional es especialmente marcado: desde sus inicios, la docencia de escritura no-literaria persuasivamente comunicativa se ha preguntado cómo se podría enseñar sistemáticamente un proceso de escritura entendido como vía de indagación y descubrimiento, que abordara la interdependencia entre el conocimiento formal y el experimental, especialmente cuando la competencia de un escritor requiere flexibilidad y adaptabilidad (Danberg, 2010). Esta variedad de la poética docens que es la escritura creativa puede beneficiarse de la teoría del pensamiento disposicional desarrollada en la enseñanza de la retórica aplicada a la composición de textos, asumiendo el modo en que el conocimiento formal y experiencial, junto con el juicio y la percepción crítica, son la base para una ejecución lograda.
Si en la cultura actual no es particularmente difícil percibir el carácter de saber disposicional de la retórica, sí lo es el de la poética, debido a ciertos axiomas del Romanticismo que han llegado a topicalizarse y a apropiarse acríticamente de la esencia operativa de la escritura, como son los del talento y el genio, la autoexpresividad natural y espontánea, la inspiración, la individualidad, la originalidad y la autenticidad. Una consecuencia adversa de la incidencia de este fenómeno en la escritura creativa afecta especialmente a la dinámica colectiva del taller: el saludable ejercicio de crítica colaborativa orientado por la búsqueda de un máximo de objetividad posible queda bloqueado por la imposición de impresiones idiosincrásicamente legítimas, pero comunicativamente inoperantes (Solomon, 2007: iii-iv). De modo concomitante a este fenómeno, el énfasis en dichos conceptos de filiación romántica invisibiliza la dimensión de oficio y de saber disposicional implicada en la escritura literaria $-\mathrm{y}$ en toda escritura, en cuanto práctica cultural y social (Maclntyre, 2004) - y genera en quienes se inician unas expectativas excesivas con respecto a la supuesta operatividad de la intuición y de estados anímicos particulares como únicos o principales vectores de la escritura (Mora-Fandos, 2015b).

La marcada naturaleza de saber disposicional de la retórica también ha configurado desde sus inicios una pedagogía sofisticada y bien estructurada, en la que la escritura creativa puede encontrar referentes didácticos y dinámicas educativas análogas (Solomon, 2007: 112). De esta manera, el alumno se beneficia de un aprendizaje sólido de recursos y materiales que puede controlar para sus fines, y evitar ser controlado por ellos si cae en un seguidismo acrítico de modelos y recetas (White, 1973: 81). Inversamente, la rhetorica docens puede beneficiarse de dinámicas didácticas específicas de la escritura creativa (Hesse, 2010: 36), donde el fomento de la creatividad o de la innovación ficcional es un fin nuclear.

\section{LA DIMENSIÓN RETÓRICA DE LA POÉTICA}

Como indica Garrido Gallardo (2004: 193), todo texto literario es también un discurso susceptible de ser analizado desde la retórica, en cuanto no puede dejar de estar constituido por una cierta dimensión persuasiva. Wayne Booth (1983: 101-106) en The Rhetoric of Fiction, argumenta frente a toda estética pretendidamente neutra que con la lectura de un texto literario llega al lector una visión social, estética y moral del mundo, planteada a través de un poderoso abanico de instrumentos expresivos y recursos argumentativos. Y 
Ricoeur (1985: 447) recuerda que esta estrategia de persuasión por parte del narrador quiere imponer al lector una visión que nunca es éticamente neutra, sino que induce implícita o explícitamente a una nueva valoración del mundo de la experiencia humana, por lo que la narrativa no puede dejar de pertenecer al campo ético. Así, se debe reconocer una presencia de la retórica en la textualidad de la obra literaria, en cuanto el autor deja en el texto la huella de una intención comunicativa que ha sido fundamental para su elaboración, que puede ser notada y reconstruida como el implied author. Al comentar esta noción de Booth, Ricoeur (1985: 289) señala que junto con el sentido de 'implícito' habría que identificar también el de 'implicado', pues no cubre solo algo - un mecanismo que implícitamente orientaría la construcción de la intención retórica del texto-, sino también un alguien, una presencia cuasi personal con una postura vital que se expresa en el texto (García-Noblejas, 2004: 33). Consideramos que, además, este autor implicado en los textos literarios ocupa una posición análoga a la presencia persuasiva del ethos que el emisor retórico imprime en su propio discurso, fenómeno registrado desde la Retórica de Aristóteles (Ryan, 1984: 176).

Como argumento de la presencia de la dimensión comunicativa-retórica en los textos literarios, Booth aduce que incluso los mejores novelistas a menudo crean escenas que pueden ser innecesarias desde el punto de vista del análisis del texto como objeto lingüístico, pero justificables como guía de colaboración para el lector. En este sentido Booth va más allá de la concepción popular de la retórica como esa presencia de lo artificioso en el texto que se haría notoria en la lectura, pues hay retórica en todo texto y la intención comunicativa-retórica concreta condiciona la configuración formal. Así, se podría decir que la economía configurativa formal y la economía comunicativa son interdependientes, y que esta interdependencia preside el proceso de la escritura desde sus inicios: desde el momento en que el escritor se dice a sí mismo que ya tiene el tema de su proyecto, ha concebido el aspecto retórico de la escritura, pues el tema es comprendido como algo que puede ser hecho público, materializado en una obra que puede ser comunicada. En tanto en cuanto resulte ser un tema genuino, los medios necesarios para su comunicación surgirán de sus necesidades, y cuando la obra esté terminada, revelarán su armonía con él. Sin embargo, esto no significa que el novelista deba pensar conscientemente en su audiencia, o que los novelistas que se preocupan por sus lectores escribirán necesariamente mejor que los que no se preocupan, pues algunos autores trabajan mejor cuando consideran su escritura como autoexpresión y su técnica como autoexploración. Se puede concluir que, con independencia de cómo se defina el modo de proceder en el arte, el concepto de escribir una historia parece llevar implícita la noción de búsqueda de técnicas de expresión que hagan la obra accesible en el mayor grado posible.

Tomando el ejemplo de cómo Henry James explicaba su uso del recurso retórico de las ficelles en $\mathrm{El}$ retrato de una dama, Booth llega a la conclusión de que en un texto no hay elementos que sean solo retóricos, pues en la totalidad de la obra literaria estos elementos se han vuelto intrínsecos y operan a favor de la finalidad literaria. En la lectura ordinaria, exenta de preconceptos críticos, habitualmente se da por supuesta esta dimensión comunicativa, y no constituye una sorpresa negativa para el lector percibir que el autor ha llevado a cabo operaciones para hacer su tema accesible en la lectura. Se acepta con normalidad que el escritor es alguien que se dirige al lector, pues quiere que su obra sea leída, y que a tal efecto pone en juego sus capacidades.

Según Booth, se podría hablar (1983: 415-6) de la retórica que hay en la ficción, de los recursos retóricos que apelan de modo más o menos explícito y reconocible al posible lector para orientar y facilitar la lectura; y de la ficción como retórica en el sentido más amplio, como una dimensión de la obra literaria cuando se la considera como un acto total de comunicación. Que el profesor de escritura creativa comprenda y visibilice la dimensión retórica puede ayudar a volver más consciente al alumno del proceso de operaciones constructivas presididas por el deseo de comunicar que va implícito en la escritura de una narración literaria lograda.

\section{LAS OPERACIONES RETÓRICAS}

Un aspecto esencial de la poetica utens es el proceso creativo, tematizado en las últimas décadas por la poetica docens, que ha recogido explicaciones de los propios escritores en cuanto a sus modos de orientar la escritura y sus reflexiones sobre las distintas tareas e interrelaciones implicadas (Arana, 2003; Lee, 2005). Estas explicaciones han sido útiles para los estudios de la psicología que, desde hace décadas, vienen abordando el proceso creativo en las artes y en la vida cotidiana. A su vez, los escritores y los docentes de escritura creativa han podido beneficiarse de los resultados de estos estudios: desde la constatación de la conveniencia de fijar por escrito el pensamiento creativo en cuanto requiere una estructuración y comunicación de 
las ideas -algo particularmente esencial para un escritor - (Runco, 2009: 191); hasta la de que el proceso creativo en la escritura no sigue generalmente una linealidad, sino una serie de pasos repetidos una y otra vez en la medida en que la obra va siendo elaborada en busca de su forma definitiva (Pritzker, 2011: 530). Esta última conclusión sobre el proceso creativo psicológico en el sujeto creador encuentra su necesario correlato en la realidad procesual de la composición lingüística de un texto: reconocida desde antiguo en la rhetorica docens, es pertinente para la creación del texto literario, en cuanto la poética coincide con la retórica en la tarea de configurar bien un discurso. Como es sabido, desde antiguo la retórica sistematizó unas fases que debían seguirse para la realización de un discurso (Aristóteles, 2005; Quintiliano, 1942) y que Roland Barthes (1970: 197) sintetiza del siguiente modo:

1. Inventio (Euresis) invenire quid dicas.

2. Dispositio (Taxis) inventa disponere.

3. Elocutio (Lexis) ornare verbis.

4. Memoria (Mneme) memoriae mandare.

\section{Actio (Hypocrisis) agere et pronunciare.}

Tomás Albaladejo (1991: 57) se refiere a ellas como operaciones retóricas, y recuerda que el discurso retórico como acontecimiento que se cumple en el tiempo en copresencialidad comunicativa de emisor y receptor necesita de las dos últimas: la memorización y finalmente la ejecución oral; pero el discurso literario prescinde de ellas y se concentra en las tres primeras, en cuanto operaciones estrictamente constitutivas de discurso orientado en forma de texto destinado a un lector. Siguiendo el estudio de Albaladejo (1991: 73117), la inventio es la operación de índole semántica en sentido semiótico, de tipo semántico-extensional, por la que se obtiene el referente del texto retórico, que es la estructura de conjunto referencial formada por la serie de seres, estados, procesos, acciones e ideas que van a ser representados en dicho texto. En el ámbito de la poética esa referencialidad sería interna al propio texto, en cuanto se construye un mundo posible como referente del sentido del texto, que deja la referencia extensional suspendida (Ricoeur, 2002: 130). La dispositio se ocupa de la organización en el interior del texto, en cuanto materiales semánticointensionales - sintácticos en sentido semiótico- de los materiales semántico-extensionales proporcionados por la inventio. La elocutio es la operación de verbalización de la estructura semántico-intensional del discurso para hacerla comprensible por el receptor, por lo que en ella confluye la energía retórica de construcción textual iniciada con la inventio y continuada con la dispositio.

Consideramos especialmente útil y acertada la decisión de Albaladejo de hablar de operaciones en vez de fases, pues, en consonancia con la constatación psicológica de Pritzker sobre el proceso creativo, más que el seguimiento de una cronología de pasos o fases a modo de recetario, en la escritura literaria se da habitualmente un proceder circular o en espiral, donde las tres operaciones concurren recurrentemente al ir materializándose la forma definitiva de la obra. El diseño particular de este itinerario de recurrencias dependerá de la psicología creativa y hábitos idiosincrásicos del escritor, así como de las características concretas del tipo de proyecto literario que acomete, conformándose una realidad artística compleja, rica y en buena medida impredecible, como han señalado habitualmente los escritores (James: 2019). En ese marco de posibilidades, las tres operaciones van revelando su interdependencia con mayor claridad y vigor al ir realizándose el proceso, donde una decisión determinada en una de las tres dimensiones operativas suele generar revisiones mayores o menores - en lo que ya está decidido en las otras dos. La psicología aplicada al proceso de la escritura refuerza este aspecto de la conexión entre poética y retórica, al identificar tres actividades cognitivas principales que englobarían los distintos aspectos del esquema operacional:

1. Planificación de lo que se va a escribir.

2. Generación de un borrador.

3. Trabajo de edición y revisión (Hayes y Flower: 1980; Hayes y Nash: 1996).

Y también refleja el hecho de que puede haber diferencias en la secuencia ideal de los procesos cognitivos según el tipo de proyecto narrativo literario, por ejemplo, entre la escritura de relato y de novela (Lubart, 2009: 161).

La dimensión configuradora del texto a través de las operaciones retóricas sigue siendo un aspecto básico de la docencia de la retórica y de la composición escrita en las instituciones universitarias norteamericanas, reivindicado por algunos en el ámbito educativo hispanoparlante general (Cassany: 1995). Su implementación en la didáctica de la escritura creativa está todavía por explorar, pero consideramos que puede augurar resultados positivos (Harper, 2014: 61-62 y 2015: 9). 


\section{LOS TÓPICOS COMO INSTRUMENTO PARA LA CREA- TIVIDAD}

En sus obras Tópicos y Refutaciones sofísticas (1993), Aristóteles sitúa bajo el nombre de tópicos o lugares los entimemas demostrativos y los entimemas aparentes que funcionan como temas al servicio de la inventio. Los lugares llamados comunes, por ser de conocimiento común a todos los hombres, son especialmente accesibles y recomendables, y se reducen a algunas evidencias como lo posible y lo imposible, lo existente y lo inexistente, lo más y lo menos, lo grande y lo pequeño, etc. Sobre esta base Aristóteles concibe el trabajo inventivo del orador como una elección consciente a partir de un número fijo de posibilidades alternativas (Hernández Guerrero y García Tejera, 1994). Este planteamiento inventivo alrededor de los tópicos ha sido canónico en la tradición retórica, como se comprueba posteriormente en Cicerón y Quintiliano, quienes los reafirman como situados entre la lógica formal y la persuasión, actuando como «matrices argumentativas» estrechamente relacionadas con la producción de premisas y argumentos formales. Como señala Egglezou (2016), el retorno académico y educativo contemporáneo a los estudios retóricos y la asociación de la retórica a la noción de creatividad en el uso del lenguaje han vuelto a revelar la relación de los lugares comunes con la invención de ideas y, en consecuencia, con el trabajo de la imaginación. Egglezou propone su empleo en la escritura creativa, pues la familiarización de los alumnos con los lugares comunes sirve como base para usar, combinar, cambiar o romper reglas comunes de pensamiento y estimular la fantasía, el pensamiento divergente y el pensamiento lateral, y orientar hacia vías creativas personales. Sin embargo, como indica la autora, la transición de alumnos de escritura creativa a autores creativos necesita tiempo: los lugares comunes, como recurso a conocimientos y experiencias propios de los alumnos, facilitan en primer lugar la "creatividad regida por reglas», al asegurar la coherencia lógica de las ideas y posibilitar la imitación de patrones de expresión lingüística.

Esta experimentación con las posibilidades de los lugares comunes - sin hacer una referencia explícita a la inventio retórica - ha sido una constante en la pedagogía divulgativa de la escritura creativa en las últimas décadas: en obras de referencia como Elements of the Writing Craft (Olmstead, 1998) y Fiction Writing Demystified (Sawyer, 2003) se pueden percibir los lugares comunes entendidos en un sentido amplio, como cualidades normalmente aceptadas del comportamiento humano que se convierten en una base desde la que operar ilimitados puntos de partida creativos. La conexión de esta dinámica relacional entre lo común y lo novedoso, con los estudios de psicología cognitiva ha sido resaltada por Howard Gardner (2006), quien ha insistido en el entrenamiento de una mente disciplinada para el desarrollo efectivo de la creatividad.

El profesor de escritura creativa cuenta con este sólido patrimonio de la rhetorica docens referido a la inventio a través de los lugares comunes, para diseñar diversas estrategias didácticas que apelan tanto al conocimiento de lo común con respecto al mundo de la acción humana, como a las reglas tradicionales de la escritura literaria. Sobre ese aprendizaje, puede introducir variaciones y abrir la puerta a la necesaria creatividad del alumno.

\section{FIGURAS Y TROPOS}

Siguiendo a Garrido Gallardo (2004: 193), la poética coincide con la retórica en cuanto esta se ocupa a través de la elocutio de los medios para configurar un discurso atrayente e incluye una teoría de las figuras: los procedimientos lingüísticos utilizados para captar la atención sobre el propio discurso con el fin de lograr una configuración persuasiva deberán ser, al menos en parte, los mismos que los utilizados con el fin de lograr un efecto estético. El mismo autor (1990: 26) ha subrayado el hecho de que realmente no existe una retórica específicamente literaria, sino elementos comunes a retórica y poética que la retórica ha abordado de modo sistemático; aunque si tanto la retórica como la poética tienen necesidad de llamar la atención del lector o espectador, lo hacen según fines específicos distintos. Así, se han configurado repetidamente en la historia inventarios de figuras y tropos comúnmente útiles a los dos modos de configurar discursos, pues llaman la atención del lector sobre el texto -la función poética (Jakobson, 1975) - . Para la gran parte de la tradición de la rhetorica docens, las figuras retóricas tienen un estatuto funcional en un texto en cuanto constituyen un elemento integral del estilo y el pensamiento: como observa Quintiliano (1942), dan credibilidad a nuestros argumentos y excitan las emociones. La rhetorica docens centrada en la operación de la elocutio ha desarrollado una exhaustiva sistematización de figuras y tropos que llega hasta el siglo XX con el trabajo del Grupo $\mu$ (1970) entre otros. Estos avances se han visto complementados y enriquecidos por estudios que han resaltado también el rendimiento cognoscitivo de figuras y tropos 
(Ricoeur, 1980) en cuanto constituyen con respecto a la realidad una redescripción que se opera en el nivel de la frase. Esta dimensión cognoscitiva-imaginativa es altamente relevante para el escritor literario quien, como indica Ricoeur, mediante la creación de un mundo posible busca una ampliación imaginaria del mundo de la acción en la mente del lector.

Whitla (2009: 234-236) también ha indicado una vía de renovación de la consideración de los tropos y figuras y su aplicación a la poética, argumentando que pueden ser tomados como conceptos para el análisis del uso inusual del lenguaje en un texto, y determinar cuántas variables literarias se combinan y qué recursos de comparación, contraste o énfasis se utilizan para influir en las respuestas del lector. Al reconocer los tipos de recursos retóricos, se puede comprender el modo en que dan forma a la respuesta de la audiencia. Un análisis retórico implicará identificar las figuras dominantes y mostrar por qué cada una es relevante en cuanto a la comunicación, trascendiendo la simple función decorativa y captando, como indica Aristóteles, cómo dan "claridad» y "vivacidad» a la expresión del pensamiento. Saber cómo se utilizan determinadas figuras retóricas en un texto plantea la cuestión de por qué se utilizan de esa manera, y apunta a las estructuras y significados más amplios de un texto, y de este modo las figuras se convierten en uno de los principales medios para codificar las convenciones de la literatura. Específicamente, el estudio de las figuras puede mostrar cómo alteran y amplían las alusiones de palabras y frases, y establecen relaciones particulares de tensión o relajación, de velocidad o lentitud y de otras dinámicas dentro de oraciones, párrafos y grandes divisiones de prosa y poesía. Tales relaciones indican lo que se valora en la literatura y, por lo tanto, iluminan el poder y el conocimiento dentro de ella y sus instituciones.

\section{LA RETÓRICA COMO HERRAMIENTA ANALÍTICA PARA LA ESCRITURA CREATIVA}

Ampliando este uso de la elocutio al conjunto de las operaciones retóricas, Spang (1998: 552), siguiendo a Bryant (1973: 36 ss.), defiende la aportación crítica de la rhetorica docens a la poética, pues por su carácter analítico descubre cómo está hecho el artefacto verbal y describe la amplitud del proceso que lo configura, como respuesta adecuada a condiciones preexistentes o emergentes. Los métodos analíticos que emplea son los que puedan dar razón de modo más completo de todos los elementos del discurso, siendo el principal aporte de la crítica retórica el tipo de preguntas que formula, los fenómenos que selecciona para la observación y la perspectiva desde la que los observa. Vista así, consideramos que la crítica retórica coincide en el ámbito literario con la disciplina de la estilística, aunque esta, aprovechando los instrumentos de aquella, la amplía al correlacionar el análisis de los elementos textuales con efectos estéticos y afectivos (Dockhorn, 1968; Paz Gago, 1993). La docencia de la escritura creativa puede beneficiarse de los métodos retóricos/estilísticos, al llamar la atención sobre la conciencia crítica a la que el autor literario, en cuanto entiende la escritura como un proceso de configuración textual, recurre constantemente en la escritura de su obra: el escritor, en sentido cronológico, es el primer lector y crítico de su propia obra.

Este aspecto coincide con una de las estrategias formativas utilizadas en la escritura creativa, llamada "leer como un escritor» (Prose, 2006; Jarvis, 2011; Mora-Fandos, 2015a), entendida como una lectura atenta a las maneras en que la forma se implica en el contenido y, aunque distinguible, se vuelve inseparable de él. Ejercitado en este tipo de lectura, el alumno se hace consciente de cómo el particular lenguaje de la narración y la serie de elementos constructivos han sido conjuntados textualmente, y de esta manera reconstruye el proceso de escritura de la obra o de algunas partes, y conecta procedimientos con efectos estéticos y afectivos.

\section{CONCLUSIONES}

La escritura creativa como docencia para la formación de escritores literarios en un contexto universitario es una disciplina flexible en sus implementaciones, capaz de apropiarse de recursos conceptuales y dinámicas didácticas provenientes de otras disciplinas. Como manifestación contemporánea de la poetica docens, puede reavivar la multisecular relación entre la poética y la retórica y hacer suyo el depósito común de medios dirigidos a la confección lograda de discursos.

Esta finalidad convergente entre poética y retórica permite a la escritura creativa ahondar en su propia naturaleza de saber dispositivo, en la comprensión de su dimensión retórica, en las operaciones configurativas del discurso y sus posibilidades para el proceso de la escritura, y en el equipamiento heurístico crítico que le permite acrisolar la calidad de la producción literaria.

Esta implicación de la retórica puede actuar como factor regulador en la organización de la diversidad 
de medios de los que dispone la escritura creativa, pues redimensiona así los aspectos de tipo psicológico heredados del Romanticismo, integrándolos en una práctica productiva donde el genio y las reglas de producción se coimplican necesariamente (Vigo 2003: 151-152). La experiencia reciente entre investigadores y docentes de la escritura creativa en los ámbitos preuniversitarios y universitarios norteamericanos - en los niveles de grado y de posgrado- indica una voluntad de abrir la disciplina a relaciones con las de la retórica y la composición escrita; que, a la vez, se benefician de las dinámicas y conceptos propios de la escritura creativa.

La escritura creativa se distinguió inicialmente de la disciplina de la retórica para determinar y ahondar en su propia esencia y fines. Desde su pluriforme estabilidad actual se encuentra en condiciones de restablecer relaciones con ella en el ámbito de la formación de escritores en la universidad. Unas relaciones que pueden retomar la estrecha relación multisecular entre poetica y rhetorica y contribuir al desarrollo de ambas disciplinas.

\section{REFERENCIAS}

Albaladejo, Tomás (1991). Retórica. Madrid: Síntesis.

Anónimo (1997). Retórica a Herenio. Madrid: Gredos.

Arana, Marie (2003). The Writing Life: Writers on How They Think and Work: a Collection from the Washington Post Book World. New York: Public Affairs.

Aristóteles (2005). Retórica. Madrid: Gredos.

Barthes, Roland (1970). L'ancienne rhétorique: Aide-mémoire. Communications, 16 (1): 172-223. https://doi. org/10.3406/comm.1970.1236

Booth, Wayne Clayson (1983). The Rhetoric of Fiction. Chicago: The University of Chicago Press. https://doi.org/10.7208/ chicago/9780226065595.001.0001

Bryant, Donald Cross (1973). Rhetorical Dimensions in Criticism. Baton Rouge: Louisiana State University Press.

Cañelles, Ramón y Álvarez, Chema (2007). A modo de introducción. Talleres de escritura: Una historia en construcción. En: Ramón Cañelles y Chema Álvarez (eds.). Escritura Creativa: cuaderno de ideas. Madrid: Ediciones y Talleres de Escritura Creativa Fuentetaja.

Cassany, Daniel (1995). La cocina de la escritura. Barcelona: Anagrama.

Cicerón, Marco Tulio (2002). Sobre el orador. Madrid: Gredos.

Coto, Benigno Delmiro (1994). Los talleres literarios (historia y propuestas). En: Carlos Lomas (coord.). La enseñanza de la lengua y el aprendizaje de la comunicación. Gijón: Trea, 109-148.

Damschen, Gregor (2011). Saber-cómo disposicional vs. Saber-que proposicional. Universitas Philosophica, 57 (2): 189-212.
Danberg, Robert (2010). Rhetorical Thinking as Dispositional: An Analytical Framework for Teachers. Writing Program - Dissertations 26. Disponible en: https://surface.syr.edu/wp_etd/26

Dockhorn, Klaus (1968). Macht und Wirkung der Rhetorik. Vier Aufsätze zur Ideengeschichte der Vormoderne. Bad Homburg: Verlag Gehlen.

Egglezou, Foteini (2016). The use of common topics in teaching creative writing. Retoric and Communications, 23. Disponible en: http://rhetoric.bg/foteiniegglezou-the-use-of-common-topicsin-teaching-creative-writing [Fecha de consulta: 10 octubre de 2020].

Emerson, Ralph Waldo (1964). Selected Writings. New York: Modern Library.

Fenza, David (2000). Creative Writing \& Its Discontents. The Writer's Chronicle. Disponible en: https://eric. ed.gov/?id=ED462703

García-Noblejas, Juan José (2004). Resquicios de trascendencia en el cine. «Pactos de lectura» y "segundas navegaciones» en las películas. En: Rafael Jiménez Cataño y Juan José García-Noblejas (eds.). Poetica \& Cristianesimo, Roma: Edusc, pp. 29-70.

Gardner, Howard (2006). Five Minds for the Future. Boston, Massachusetts: Harvard Business School Press.

Garrido Gallardo, Miguel Ángel (1990). Homo Rhetoricus. En: Miguel Ángel Garrido Gallardo (ed.). Actas del III Simposio Internacional de la Asociación Española de Semiótica, Madrid: Universidad Nacional de Educación a Distancia, pp. 23-38.

Garrido Gallardo, Miguel Ángel (2004). Nueva introducción a la teoría de la literatura. Madrid: Síntesis.
Grupo $\mu$ (1970). Rhétorique générale. Paris: Larousse.

Harper, Graeme (2014). The Future for Creative Writing. Pondicherry: Wiley Blackwell. https://onlinelibrary.wiley.com/doi/ book/10.1002/9781118476826

Harper, Graeme (2015). Creative Writing and Education: An Introduction. En: Graeme Harper (ed.). Creative Writing and Education. Bristol U.K.: Multilingual Matters, 1-16. https://doi. org/10.21832/9781783093540-004

Hayes, John y Flower, Linda (1980). Identifying the organization of writing processes. En: Lee Green y Erwin Steinberg (eds.). Cognitive Processes in Writing. Hillsdale: Erlbaum, pp. 3-30.

Hayes, John y Nash, Jane (1996). On the nature of planning in writing. En: Michael Levy y Sarah Ransdell (eds.). The Science of Writing: Theories, Methods, Individual Differences, and Applications. Mahwah: Erlbaum, pp. 29-55.

Hernández Guerrero, José Antonio y García Tejera, María del Carmen (1994). Historia breve de la Retórica. Madrid: Síntesis.

Hesse, Doug (2010). The Place of Creative Writing in Composition Studies. College Composition and Communication, 62 (1): 31-52.

Jakobson, Roman (1975). Ensayos de Lingüística General. Barcelona: Seix Barral.

James, Henry (2019). El arte de la ficción. Madrid: Fragua.

Jarvis, Tim (2011). 'Pleasure balks, bliss appears' or 'The apparatus shines like a blade': Towards a theory of a progressive reading praxis in Creative Writing pedagogy. Text: Journal of Writing and Writing Courses, 15 (2). Disponible en: http:// textjournal.com.au/oct11/jarvis.htm 
Lee, Maurice (2005). Writers on Writing: The Art of the Short Story. Westport: Praeger.

Lewis, Clive Staples (1954). English Literature in the Sixteenth Century, excluding Drama. The Oxford History of English Literature (vol. III). Oxford: Clarendon Press.

Lubart, Todd (2009). In Search of the Writer's Creative Process. En: Scott Kaufman y James Kaufman (eds.). The Psychology of Creative Writing. Cambridge: Cambridge University Press, pp. 149-165. https://doi.org/10.1017/ CB09780511627101.011

MacIntyre, Alasdair (2004). Tras la virtud. Barcelona: Crítica.

McGurl, Mark (2005). The Program Era: Pluralisms of Postwar American Fiction. Critical Inquiry, 32 (1): 102-129. https:// doi.org/10.1086/498006

McGurl, Mark (2009). The Program Era: Postwar Fiction and the Rise of Creative Writing. Cambridge: Harvard University Press. https://doi. org/10.2307/j.ctvjsf59f

Mearns, William Hughes (1929). Creative Power. Garden City: Doubleday.

Mora-Fandos, José Manuel (2015a). La lectura tridimensional. Una propuesta para la escritura creativa. Cálamo-Faspe, 64: 16-22.

Mora-Fandos, José Manuel (2015b). T. S. Eliot en el aula de escritura creativa: «La tradición y el talento individual». Nueva Revista de Política, Cultura y Arte, 153: 34-43.

Myers, David Gershom (1993). The Rise of Creative Writing. Journal of the History of Ideas, 54 (2): 277-297. https://doi. org/10.2307/2709983
Myers, David Gershom (2006). The Elephants Teach. Creative Writing Since 1880. Chicago: The University of Chicago Press.

Obligado, Clara (2014). Talleres literarios. Orígenes y trayectoria. Puentes de crítica literaria y cultural, 2: 102-107.

Olmstead, Robert (1998). Elements of the Writing Craft. Story Press Books.

Paz Gago, José María (1993). La estilística. Madrid: Síntesis.

Pritzker, Steven (2011). Writing and Creativity. En: Mark Runco y Steven Pritzker (eds.). Encyclopedia of Creativity (2nd ed.). Academic Press, pp. 525-532. https://doi.org/10.1016/B978-0-12375038-9.00237-5

Prose, Francine (2006). Reading like a Writer. A Guide for People Who Love Books and for Those Who Want to Write Them. New York: HarperCollins.

Quintiliano, Marco Fabio (1942). Instituciones oratorias. Madrid: Librería y Casa Editorial Hernando.

Ricoeur, Paul (1980). La metáfora viva. Madrid: Ediciones cristiandad.

Ricoeur, Paul (1985). Temps et récit. 3. Le temps raconté. Paris: Éditions du Seuil.

Ricoeur, Paul (1997). Retórica, poética y hermenéutica. En: Gabriel Aranzueque (ed.). Horizontes del relato: lecturas y conversaciones con Paul Ricœur. Madrid: Universidad Autónoma de Madrid, pp. 79-89.

Ricoeur, Paul (2002). Del texto a la acción. Ensayos de hermenéutica II. México: Fondo de Cultura Económica.

Runco, Mark (2009). Writing as an Interaction with Ideas. En: Scott Kaufman y James Kaufman (eds.). The Psychology of Creative Writing. Cambrid- ge: Cambridge University Press, pp. 180-195.https://doi.org/10.1017/ CBO9780511627101.013

Ryan, Eugene (1984). Aristotle's Theory of Rhetorical Argumentation. Montreal: Les Éditions Bellarmin.

Sawyer, Thomas (2003). Fiction Writing Demystified: Techniques that Will Make You a More Successful Writer. Malibu, California: Ashleywilde.

Solomon, Ryan (2007). In Search of Copia: Using Rhetoric to Teach Creative Writing. All Thesis and Dissertations 1011. Disponible en: https://scholarsarchive.byu.edu/cgi/viewcontent. cgi ?article $=2010 \&$ context $=$ etd

Spang, Kurt (1998). De Nuptiis Rhetoricae et Poeticae. Anuario Filosófico, 31: 543-565.

Vigo, Alejandro (2003). Ética y creatividad. Libertad, sentido y reglas en contextos práctico-operativos. Tópicos, 11: 137 160. https://doi.org/10.14409/topicos. v0i11.7446

Vigo, Alejandro (2011). Caridad, sospecha y verdad: la idea de la racionalidad en la hermenéutica filosófica contemporánea. En: Francisco de Lara López (ed.). Entre fenomenología y hermenéutica. Plaza y Valdés, pp. 165-202.

Wendell, Barrett (1893). English Work in the Secondary Schools. School Review, 1: 638-667.

White, James Boyd (1973). The Legal Imagination: Studies in the Nature of Legal Thought and Expression. Boston: Little, Brown and Co.

Whitla, Robert (2009). The English Handbook: A Guide to Literary Studies. Singapore: John Wiley \& Sons. 